\title{
Introduction to special issue on e-voting
}

Jurlind Budurushi, Stephan Neumann, Karen Renaud and Melanie Volkamer

This is the accepted manuscript (c) 2017, Elsevier Licensed under the Creative Commons AttributionNonCommercial-NoDerivatives 4.0 International: http://creativecommons.org/licenses/by-nc-nd/4.0/

\section{(c) EY-NG-ND}

The published article is available from doi: http://dx.doi.org/10.1016/j.jisa.2017.12.003 


\title{
Introduction to Special Issue on E-Voting
}

\author{
Editors: \\ Jurlind Budurushi ${ }^{1}$, Stephan Neumann ${ }^{2}$, Karen Renaud ${ }^{3}$, Melanie Volkamer ${ }^{4}$ \\ 1 Detecon International GmbH jurlind.budurushi@detecon.com \\ 2 Technische Universität Darmstadt stephan@stephanneumann.it \\ 3 Abertay University, Scotland \& University of South Africa k.renaud@abertay.ac.uk \\ 4 Karlstad University \& Technische Universität Darmstadt melanie.volkamer@secuso.org
}

Electronic voting refers to any process that benefits from the use of some kind of electronic technology by the election authorities in order to run elections. The use of technology in election processes can vary from simple cases, such as electronic voter registration, to more complex cases, such as vote casting, tallying of votes, and communication of election outcomes. However, as recent cases demonstrate, the use of technology in elections does not only pose technical challenges, but also has political and social implications. A case in point is the 2016 presidential election in the United States [1]. Research into electronic voting brings together a wide range of research disciplines such as computer science, psychology, sociology, politics and legal sciences.

From a legal-technical perspective, electronic voting systems have to address a variety of requirements in the most appropriate way. On the one hand the secrecy of the vote is indispensible and must be preserved by organizational and technical means. On the other hand, transparency of the vote is of fundamental importance to foster public trust in any electronic system and contributes towards general confidence in the election outcome.

While at first sight, these requirements might seem to conflict, many systems satisfying these requirements have been proposed and deployed in practice [2]. The actual deployment of these systems does not always lead to widespread acceptance. For instance, Canada has carried several trials [3], but has not yet committed to widespread use of electronic voting [4][5]. Estonia has embraced electronic voting. Estonia introduced remote electronic voting for elections in 2005 [6][7], and since then has held six nation-wide elections using remote electronic voting channels. Even though the Netherlands were one of the earliest adopters of electronic voting, they have no discontinued this practice after it was demonstrated that the voting machines could easily be compromised [8].

Research strive to find new ways of tailoring electronic voting technologies to meet the needs of legal regulations, technical advances, and the dynamics of social and psychological contexts. To that end, new application areas of voting technologies arise, such as proxy voting, mobile voting, or spontaneous and secure decision-making voting in small communities. These new directions, however, also pose new challenges. Among others, these new challenges include identifying and defining requirements, such as usability and practical feasibility, as well as developing new proposals to address these requirements.

A number of papers were selected for this issue, each of which makes a significant contribution to the debate on new directions in electronic voting.

The work by Ullrich addresses the question to what extent privacy of a small election is at risk due to unanimous voting. The author applies his theoretical investigation to a real-world election in Germany and reports interesting findings as well as possible mitigation techniques.

The work by McIver et al. seamlessly connects to the work by Ullrich. The authors build a privacy model, which helps them to quantify the information leakage due to the publication of election-related information. Thereby the authors build the foundation for defining an adequate trade-off between secrecy of the votes and enforcing the public nature of the elections.

AboSamra et al. particularly address the needs of developing countries which slowly aim at enhance or replace their conventional voting systems by voting technology. Building upon the well-studies hybrid voting system Pret-a-voter, the authors present the implementation of their voting system and report their findings from a conducted voting simulation with the proposed system.

Willemson contributes a thought-provoking essay on the faux obstacles and objections that are used to oppose electronic voting. Writing from an Estonian perspective, a country that has embraced electronic voting, he gives the reader a great deal of food for thought. 
The final paper comes from Simpson and Storer, exploring the idea of delegating voter verification to a trusted third party. The authors propose an extension of two hybrid systems, Prêt à Voter and Scantegrity, to enable such thirdparty verification.

To conclude, the papers included in this special issue contribute by highlighting the challenges of electronic voting from a number of different perspectives. They provide readers with an overview of the complex challenges and possible solutions in the exciting and evolving domain of voting technology.

[1] http://www.stamfordadvocate.com/technology/businessinsider/article/JAMES-CLAPPER-US-intelligence-assessment-of12222561.php, last accessed 27.09.2017

[2] A comprehensive view of the state of electronic voting in all the countries in the world can be found at https://www.evoting.cc/en/it-elections/world-map/, last accessed 27.09.2017

[3] An excellent report—City of Toronto RFP \#3405-13-3197— can be found at https://assets.documentcloud.org/documents/1310860/toronto-internet-voting-security-report.pdf, last accessed 27.09.2017

[4] Goodman, N. J. (2014) Internet voting in a local election in Canada. In: The Internet and Democracy in Global Perspective. Springer, pp 7-24

[5] Pammett, J. H, Goodman, N. (2013) Consultation and evaluation practices in the implementation of Internet voting in Canada and Europe. Elections Canada, Research Report, Ottawa

[6] Maaten, E. (2004) Towards remote e-voting: Estonian case. In: Prosser A., Krimmer R. (eds) Electronic Voting in Europe, vol 47. LNI, GI, pp 83-100

[7] Madise, Ü., Martens, T. E-voting in Estonia 2005. the first practice of country-wide binding internet voting in the world. In: Krimmer [34], pp 15-26

[8] Gonggrijp, R., Hengeveld, W. J (2007) Studying the Nedap/Groenendaal ES3b voting computer: A computer security perspective. In: EVT'07: Proceedings Of the USENIX/Accurate Electronic Voting Technology Workshop 2007 on Electronic Voting Technology Workshop. USENIX Association, CA, USA 